\title{
Reuse of Waste Sugarcane Agribusiness and Green Power Generation
}

\author{
L. R. Holanda and F. S. Ramos
}

\begin{abstract}
Currently, the biggest challenge is to maintain the productive sector and increase competitiveness while serving the needs of stakeholders, and is clearly more complicated with the inclusion of the environmental variable. Within a highly competitive environment, the waste of sugarcane production ends up being a waste of money, they represent a part of the investment that does not generate revenue. This paper presents through a literature review, a study of the entire production process of the sugar and alcohol industry, identifying the waste that it produces in the process, such as straw and sugarcane bagasse, wash water from sugarcane, filter cake, vinasse and carbon dioxide. And, with the result that management of such waste through the determination of possible alternatives to the use of these, producing byproducts, and generating a new green energy source, maximizing their productivity and profit as well as improving the environmental awareness of the company.
\end{abstract}

Index Terms - Agribusiness, green energy, waste.

\section{INTRODUCTION}

Since the 1990s, companies have realized the need to combine growth with environmental conservation by noting that the concern over natural resources and their rational use could provide gains in an increasingly competitive and globalized market.

Today, in the face of pressure from stakeholders and the emergence of more stringent legislation, the performance on environmental issues in an organization has become a matter of competitiveness and their own survival, in the other words, the eco-efficiency has become a prerequisite essential for competition in the global market.

Therefore, the technical management of waste production in enterprises has become increasingly important and has been-identified as a strategic element in production management. Waste, which previously degraded the environment and harmed the health of the population through management can minimize costs, maximize production, and improve the image of the company's sustainability, opening new consumer markets.

Among the different agro-industrial complexes present in the Brazilian economy, one that stands out is the sugarcane agro-industrial complex. Competitive pressures in this sector are increasing since it is important for the generation of surplus in trade balance. However, productive processes and steps that lead negative environmental impacts are part of the

Manuscript received April 19, 2015; revised September 22, 2015. This work was supported in part by the Coordination of Improvement of Higher Education Personnel (CAPES).

The authors are with the Production Engineering Department, Federal University of Pernambuco, Brazil (e-mail: laryssarholanda@hotmail.com, ramosfs@gmail.com). trajectory of agri-business and have been exacerbated in recent years.

Being an industry with high pollution potential, the Brazilian sugarcane industry generates annually, in the form of waste, about 320 billion liters of vinasse, 88 million tons of filter cake, and 92 million tons of bagasse. The loss of money arising here is not the use of such waste [1].

Thus, it becomes important to examine the possibilities of use and control of such waste and possible alternatives for its use. The purpose of this paper is to analyze a possible waste management for the sugar industry in order to reuse them in the production of other products, decreasing environmental impacts, improving the perception of sustainability to stakeholders across the industry, and diversifying production while increasing competitiveness.

This paper is structured as follows: Section II presents the method that was adopted to achieve the objectives; Section III shows the sugarcane production process, its stages and waste; Section IV presents ways to reuse waste, i.e. how, through management, it could reuse these waste produces other products, such as green energy, and maximizing the income of the company as well as improving environmental "picture" of the company; and Section V presents some conclusions.

\section{Methodology}

This study was done through a literature review, which was carried out a search for texts that deal with the sugarcane agro-industrial activity, waste materials, as well as possibilities for these destinations. To achieve the objective of the study, several articles and journals references cited in the study were consulted.

\section{THE SUGAR AND ETHANOL INDUSTRY}

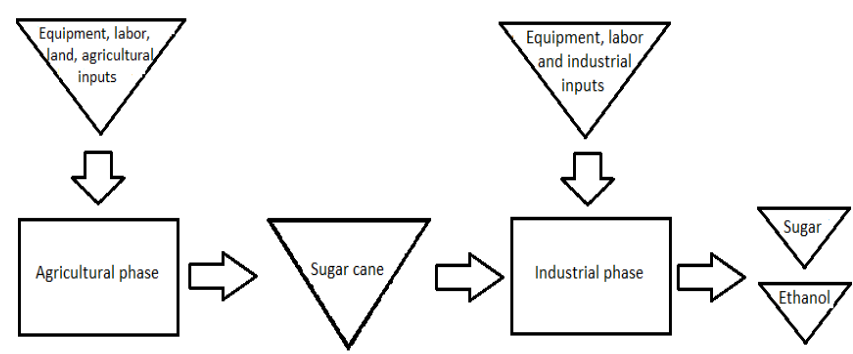

Fig. 1. Flow of the production process of the sugarcane agribusiness system.

Sugar mills and ethanol in Brazil have two phases of the production process, an agricultural and other industrial, forming so-called agro-industrial systems. A flow of the summarized production process is illustrated in Fig. 1. 


\section{A. Farm Phase}

According to [2], the agricultural phase has as its main steps in soil preparation, planting, cultural practices, harvesting, and transporting to the mill. The end product of this phase is the sugar cane and it is this operation that causes significant environmental impact and therefore deserves attention of the burning of sugar cane straw. Fig. 2 shows the flow of activities in the agricultural phase.

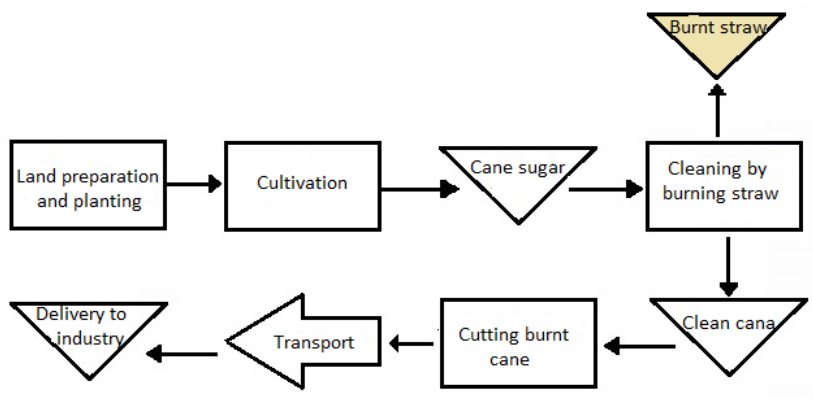

Fig. 2. Operational Flow sugarcane farming.

The operations of preparation, planting, and cultivation are made the same way as other cultures. Manual harvesting of sugar cane is widely used because of the ease of getting labor at a low cost. According to [3], this practice brings some inconveniences occasioned by the necessity of straw burning, such as reduction of raw material due to the phenomenon of exudation (sugar loss through perspiration cane), air pollution, and degeneration of growing soil.

\section{B. Industrial Phase}

In the manufacturing phase, the final products are sugar and ethanol. According to [4], two types of sugar are produced in Brazil, raw sugar and white crystal. Raw sugar has a lower degree of purity and is sold as feedstock for refineries while the crystal undergoes a more thorough clarification process providing the best quality. Ethanol is produced as a hydrate (95-96\%) to meet the demand of the chemical industry and as a beverage or anhydrous (greater than $99 \%$ by volume) as fuel.

According to [3], the sugar and ethanol industry needs considerable amounts of water in their processes and operations. Thus, their most appropriate location is near a source of water and it is essential that it is close to the source of raw material, i.e., the cane fields.

As [4] and [2] stated, the industrial phase is depicted in Fig. 3 and consists of the following steps:

Receipt of sugarcane: In this step, the weighing and sampling, for purposes of determining the sucrose content and percentage of soluble solids, is taken. Also examined is the fiber content. Downloads are mechanized and the sugar cane should not be store so as to avoid losing its sucrose. One should proceed to the next stage of production.

Wash: Consists of removing mineral impurities that it was adding to the cane along the agricultural production stage. Effects are washed sugarcane water spray immediately before the entry of this input in the wake processing. The wastewater from washing sugarcane has high pollution potential and it requires the agro-industrial to install this effluent treatment systems prior to disposal at a spring or farming units.

Preparation and milling: Clean cane enters a treadmill which is minced and the fibers are broken, These operations are aimed at the destruction of the shell, the disruption of cellular vessels which are located broth and standardization of facilitating the process of sugarcane juice extraction.

It is worth noting that the final product of the milling process of sugar cane juice is a dilute solution of sucrose that generates duly processed sugar. The bagasse is the by-product of the milling process; this material consists primarily of plant fibers (cellulose).

Purification: The purification operation aims to remove coarse impurities (stones, soil and bagasse) of the juice extracted from sugarcane through screening and chemistry juice clarification. Then, the broth is filtered and the precipitated impurities, called filter cake, are collected.

Concentration and cooking: The concentration of sucrose is to raise the temperature of the broth by evaporating the water contained in the mixture is done, the broth becomes syrup is cooked and so that spontaneous crystallization of sucrose occurs. The final product of this operation is a mixture of crystals and honey.

Spin: The mass, consisting of crystals and honey, is subjected to a centrifugal, crystals, called sugar, are retained in the basket centrifuge and are displaced for drying, packaging and storage. The mass of honey from lower purity, which was boiled and centrifuged several times, is termed the final molasses or honey, and is sent to distillation for the production of ethanol.

With molasses the manufacture of ethanol is initiated.

Preparation of wort and yeast: The wort is a liquid made from dissolved molasses and must be prepared to be able to fermented. For the preparation, it is necessary to correct acidity and correct supplementation of nitrogen and phosphorus. The preparation of yeast is crucial for a satisfactory multiplication of yeast capable of transforming the sugars of the wort into ethanol and carbon dioxide.

Fermentation: Fermentation adds the yeast to the wort, initiating the first step of continuous fermentation process. Then the product is repressed to a decanter where it removes some of the remaining bacteria. In this process, there is a great elimination of carbon dioxide in the atmosphere. The excess yeast is passed back in the process and the product of the fermentation of wine call is routed to the distillery.

Distillation: The distillation wine is purged twice in a distillation column. The first eliminates the esters and aldehydes and the second separates the vinasse and obtains the ethanol.

Each step of the manufacturing process results in a final product, which is forwarded to the next stage and a byproduct that cannot always be reused by the system, generating a residue that must be disposed. Which shows the importance of a management system that identifies, qualitatively and quantitatively each of these wastes so that they have an economic and environmental reuse [4]. In Fig. 3, we can observe the production process as well as the residues generated (highlighted).

\section{Residues of Sugarcane Production}

According to the literature of [2], [3], and [4], the key residues of the sugarcane agribusiness are:

The straw: Part of the trash, which consists of green leaves, 
pointers, straw, and other plant material itself beyond the earth. The straw burning the sugarcane fields causes air emissions of particulate matter, hydrocarbons, carbon monoxide, carbon dioxide, nitrogen oxides, and sulfur oxides. The soot and smoke reaches urban centers, miles away, causing widespread nuisance to residents. Respiratory problems of the population increase and undesirable aesthetic effects are generated in the atmosphere and in backyards, causing an increase in water consumption for cleaning [2].

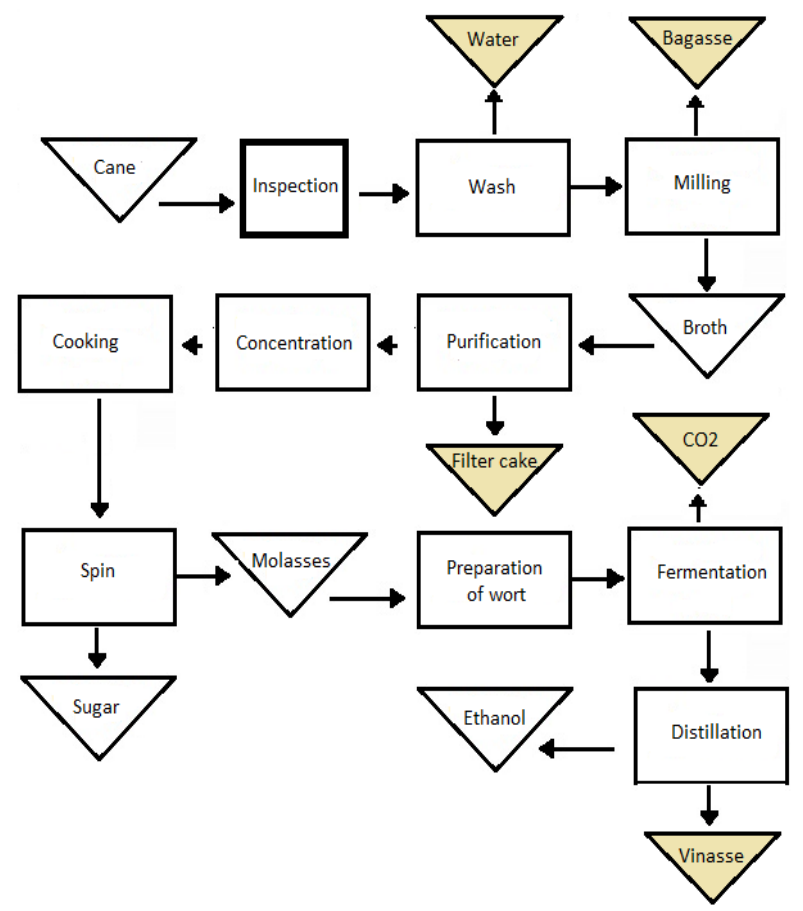

Fig. 3. Flowchart of the production process of a sugar and ethanol.

Wash water from sugarcane: Water, when leaving the washing process of the cane, carries with it a high organic load. If disposed of without treatment, the drinking water causes damage such as the death of fish.

Sugarcane bagasse: We present the most significant solid waste generated by virtue of quantity between 250 and $260 \mathrm{~kg}$ per tonne of cane processed, removing the need for large storage areas [3].

Filter cake: Mix the crushed bagasse and sludge resulting from the settling of juice clarification process. For each ton of sugarcane around $25 \mathrm{~kg}$ of pie is obtained. In its composition, the concentration of various metals is identified: aluminum, manganese, zinc and iron. Due to its organic quality, the residue has a high biochemical oxygen demand, which causes pollution adduced towards the water bodies. After the industrial separation, such waste is stored accumulating in areas outdoors, directly on the ground.

Carbon Dioxide: In the stages of fermentation and distillation occur large emissions of carbon dioxide. It is estimated that for every 1,000 liters of ethanol produced 800 $\mathrm{kg}$ of $\mathrm{CO}_{2}$ are emitted, harming the health of living beings and contributing to the serious problem of the greenhouse effect, which can already feel climate change.

Vinasse: The residue of ethanol distilling process. It is a highly polluting effluent and comes in a large volume, from 10.3 to 11.9 liters per liter of ethanol, making it difficult to transport and dispose of. This liquid residue features: high temperature, acidic $\mathrm{pH}$, corrosivity, high potassium, and significant amounts of certain nitrogen, phosphorus, sulfates, and chlorides, among others. Its dumping into rivers and lakes caused the phenomenon of eutrophication and fish death.

Thus, it would be of great importance to conduct a waste management where you give proper allocation to these, minimizing the harmful effects to the environment, and to maximize reuse mill production, increasing the competitiveness of the industry.

\section{WASTE MANAGEMENT}

According to [5], environmental preservation currently occupies a significant portion of investment and administrative efforts in all sectors of economic activity, becoming a strategic issue that involves innovation, adoption of cutting edge technology, and increased productivity. In this context, increasing the domestic industry has been concerned with issues involving direct and indirect natural resources in their production processes.

Within this framework it is important to highlight several factors that influence organizations to adopt environmentally responsible positions, such as the improvement of image in society, reducing costs of production processes by adopting management programs aimed at solving environmental problems, the requirement of the consumer market, and the need to adapt to prevailing environmental laws and commonalities in the country, among others [4].

According to [6], environmental legislation should be able to trigger innovations in manufacturing to reduce product costs and increase its value. The author points to two possibilities for innovation within the framework of environmental regulation. The first is the minimization of the costs of pollution control or treatment, highlighting the advantage of raising funds which are incorporated into pollution through recycling, reuse of waste, converting materials, and others.

The second innovation is the possibility of attacking the root causes of pollution by improving the use of resources. That is, the polluter may, form changes in their production processes, types of inputs used and products, increase their productive output, cut emissions of pollutants and reduce total costs.

From the observations of [6], one realizes that innovations aimed at environmental regulations, when properly applied, can reduce costs, boost resource productivity, and eliminate pollutants.

The biggest challenge is to maintain the productive sector and increase competitiveness while serving the needs of stakeholders, which was clearly more complicated with the inclusion of the environmental variable [5].

According to [7], in a highly competitive environment, the waste of sugarcane production ends up being a waste of money because that does not recycle this waste cause the purchase of supplies, equipment wear, and the costs involved transporting and storing of waste.

Thus, it becomes important to analyze possible alternatives for its use since the Brazilian sugarcane sector annually generates about 320 billion liters of vinasse, 88 million tons of filter cake, and 92 million tons of bagasse. 


\section{A. Management of Waste from Sugarcane Agribusiness}

According to literature, the following could be identified as possible reuses for major waste of sugarcane production in order to diversify and increase production and reduce costs and environmental impacts.

\section{1) Straw cane}

According to [3], there is a negative energy balance, resulting from the loss of energy released at its burning, still in the fields. This loss is quite significant, considering that one hectare of crop residue has the equivalent of 29 barrels of oil or 9600 liters of ethanol energy power.

Thus, [3] proposes the straw burning boiler for steam generation and leveraging it as an alternative energy source. Studies in Brazil show that bagasse showed calorific value of $1,790 \mathrm{kcal} / \mathrm{kg}$, straw $3,600 \mathrm{kcal} / \mathrm{kg}$ and hands with straw $2,280 \mathrm{kcal} / \mathrm{kg}$. It has a way of allocating this residue generating steam and power, in the other words, maximizing the plant's production.

\section{2) Bagasse sugarcane}

The final bagasse is the fibrous solid matter generated at the output of the last mill after juice extraction.

For [3], the surplus bagasse can have the following uses as raw material:

- In the power generation by burning in boilers;

- In the manufacture of fiberboard, used in construction;

- In the manufacture of paper pulp (cellulose) such as high-yield pulp;

- In the manufacture of plastic or various solvents used in industry.

According to [4], a ton of sugar provides, through the burning of bagasse, the equivalent to $70 \mathrm{~kW} / \mathrm{h}$ of energy. Thus, the reuse of this waste for power generation has been diversified in the production plant. The author compared the burning of bagasse with other fossil fuels and says it is cleaner, causing less environmental impact since virtually no sulfur compounds is released with bases as $\mathrm{SO}_{2}$ or $\mathrm{SO}_{3}$ relatively common at burning fuel. Moreover, its burning is slow with a low temperature flame providing little training nitrous oxide.

\section{3) Filter cake}

For [4], the filter cake can be reused as a substitute for the traditional potash inputs, particularly in the planting operation. The filter cake should be placed in the groove along with the changes of cane sugar. Thus, the use of this waste would reduce the cost of inputs for soil preparation.

\section{4) Stillage}

An apparent solution to the rational disposal stillage in what is currently called fertigation, i.e., the use of this product rich in organic matter applied in nature in areas planted to sugarcane [4].

For [3], proposes the use of stillage for methane production, representing an auxiliary power source. According to the author, methane is a gas produced during decomposition of organic waste due to bacterial activities.

Biogas production is obtained through an anaerobic fermentation process involving several stages, each of which operates on a microbiological agent.

Also according to [3], many studies have proved the technical feasibility of anaerobic digestion of vinasse, starting from the assumption that the technology of anaerobic digestion of vinasse, called "clean technology", directly contributes to sustainable development by offering the use of this waste for biogas production, which could be burned in a turbine to drive an electricity generator.

Besides, electricity stillage, after passing through the anaerobic digestion process, can be also used as bio-fertilizer in fertigation process (irrigation and fertilization) without harming its characteristics of organic fertilizer.

The plant would minimize costs and maximize fertilizer production through the production of methane.

\section{5) Water washing cane and carbon dioxide $\left(\mathrm{CO}_{2}\right)$}

Reference [8] proposes, through the wastewater from washing of sugarcane and the carbon dioxide emitted in the ethanol fermentation process, the cultivation of microalgae and, through these microorganisms, generate electricity through the burning of their dry weight in a boiler.

These microalgae have the energy efficiency for 1000 liters of ethanol. The production of $800 \mathrm{~kg}$ of $\mathrm{CO}_{2}$ emitted is enough to produce $470 \mathrm{~kg}$ of algal biomass, the amount burned generates approximately $3.82 \mathrm{MW} / \mathrm{h}$. Fig. 4 shows the flow of production proposed by [8] for microalgae at a power plant.

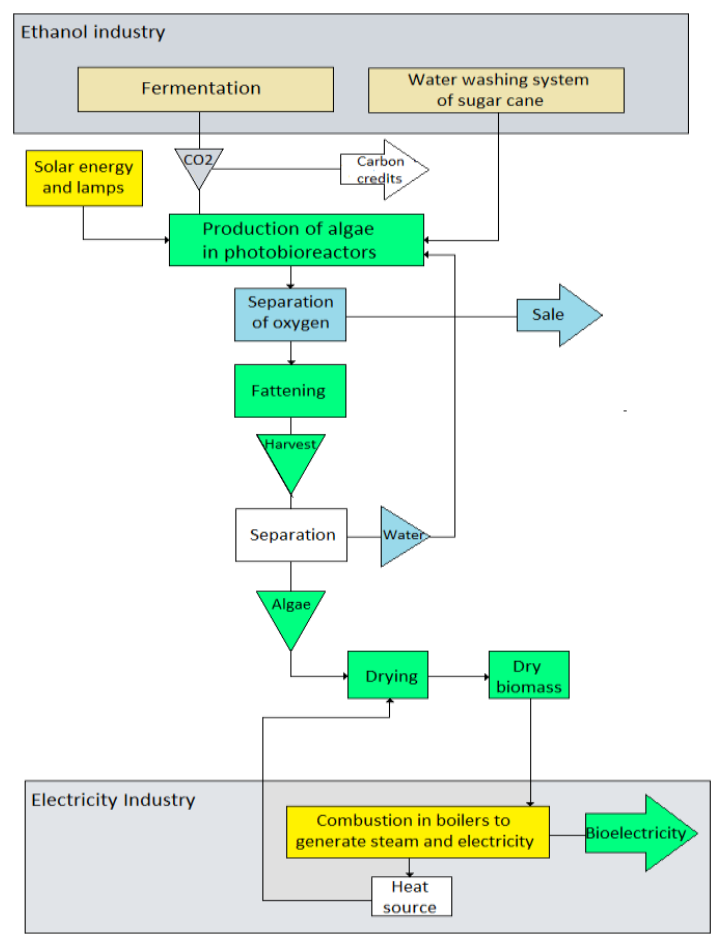

Fig. 4. Flow of microalgae production process

The production of microalgae in photo-bioreactors would be constructed in accordance with the desired quantity to be produced. In algae photo-bioreactors are lit by solar energy and lamps at night, and fed with $\mathrm{CO}_{2}$ through photosynthesis reproduce and release oxygen $\left(\mathrm{O}_{2}\right)$. For each ton of $\mathrm{CO}_{2}$ approximately $500 \mathrm{~kg}$ of $\mathrm{O}_{2}$ is absorbed. This $\mathrm{O}_{2}$ can be sold generating revenue for the production of microalgae.

After the separation of $\mathrm{O}_{2}$, algae undergo a process of fattening until reaching the harvesting process. They are then separated from the water in a process in which air is inserted beneath a compartment where the broth (water and a compound of microalgae) is stored to form many bubbles, so 
that, by a decantation process, microalgae focus on the surface of the water separating them.

In phase separation, there is a return to the recycled water containing nutrients and fertilizers remaining in the water, allowing reuse of the same as water.

Afterwards, the microalgae are extracted by a drying process in which warm water is used in a process as illustrated in Fig. 5.

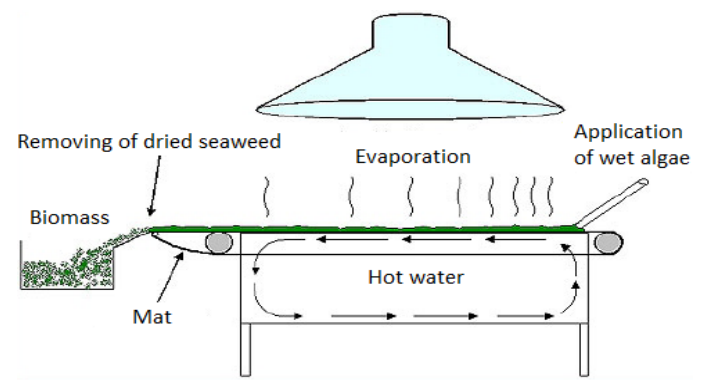

Fig. 5. Drying process of microalgae.

After drying the biomass is ready to be burned and generate electricity. The algal biomass combustion can be performed in the same boilers used in the burning of bagasse, generating bioelectricity.

The use of waste (washing water and $\mathrm{CO}_{2}$ ) in the plant will have production of microalgae to maximize their revenues through carbon credits and the sale of pure oxygen and electricity.

\section{CONCLUSION}

Environmental preservation has become a strategic issue that involves innovation, adoption of technology, and increased productivity. In this context, increasing the domestic industry has been concerned with issues involving direct and indirect natural resources in their production processes.

As seen, the sugar mills and ethanol distilleries have high pollution potential. Since the method used to obtain the raw material to the final production of sugar and ethanol, various waste and by-products are generated that could cause damage to the environment.

Waste management then reveals the great importance to sugar and ethanol industry, according to the current generation and especially for having forecast to expand production of sugar and ethanol, and consequently waste residues of this production. In addition to solving the environmental impacts caused by the production of waste, reuse of these reduces costs and increases production.

The study achieved its goal in the literature identifying the residues of the sugarcane agribusiness and possible reuse of these in order to produce other products, generate electricity and maximize the company's competitiveness and reduce environmental impacts.

It is necessary to quantify the gains and costs arising from such management and, thus, verify the quantitative impacts the bottom line but, for lack of data, this was not possible in this study. It is recommended for future work to make this quantitative analysis of these byproducts generating gain competitiveness.

\section{REFERENCES}

[1] CONAB. Cane sugar: seasons. (December 2013). [Online]. Available: http://www.conab.gov.br/download/safra/3\%20levantamento\%20.pdf

[2] J. F. Andrade and K. M. Diniz, "Environmental impacts of agribusiness of cane sugar: Grants management," Monograph Specialization, Environmental Management, University of São Paulo, p. 131, Piracicaba, Brazil, 2007.

[3] J. M. M. Paoliello, "Environmental aspects and energy potential in waste recovery of the sugarcane industry," Master dissertation, Paulista State University, p. 200, Bauru, Brazil, 2006.

[4] F. J. Piacente, "Sugarcane agribusiness and environmental management system: The case of plants located in the basins of Piracicaba, Capivari and Jundiaí Rivers," Master dissertation, State University of Campinas, p. 187, Campinas, Brazil, 2005.

[5] J. R. Santos and N. R. Abreu, "The impact of green marketing for sugarcane mills operating in Alagoas," Journal Alcance, vol. 16, no. 2, 2009.

[6] M. E. Poter, Competitive Strategy: Techniques for Analyzing Industries and Competitors, Free Press, New York, United States of America, 1980.

[7] R. P. Alvarenga and T. R. Queiroz, "Cleaner production and environmental aspects in sugar-alcohol industries," in Proc. 2nd International Workshop Advances in Cleaner Production, São Paulo, Brazil, 2009.

[8] L. R. Holanda and F. S. Ramos, "Analysis of the economic feasibility of electricity generated through microalgae," Journal Sistemas \& Gestão, vol. 6, no. 3, pp. 327-346, 2011.

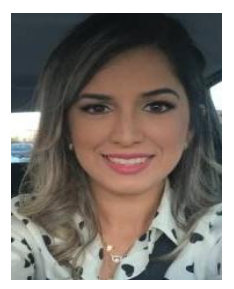

L. R. Holanda was born in the State of Alagoas, Brazil, on December 30, 1986. She is currently a doctoral student in production engineering at the Federal University of Pernambuco, Brazil. She has a master's degree in production engineering from the Federal University of Pernambuco, Brazil, 2011 and a degree in economics from the Federal University of Alagoas, Brazil, in 2009.

She has been dedicated in her later works the alternative energy sector, economic and financial analyzes of the renewable energy industry.

Holanda has published several papers in conference proceedings and journal, such as "Analysis of electricity generated by the economic feasibility of microalgae," Systems \& Management, 2011, and "Bioenergy production through microalgae in Brazil: an activity joint with ethanol plants of Brazil," in Proc. RCN Conference on Pan American Biofuels and Bioenergy Sustainability, 2014 in Recife, Brazil.

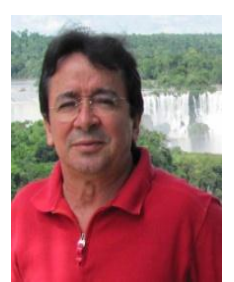

F. S. Ramos was born in the State of Paraíba, Brazil. Currently, Ramos is an associate professor and pro-rector for research affairs and graduate studies at the Federal University of Pernambuco, in Brazil. He graduated in electrical engineering from the Federal University of Pernambuco, Brazil, 1981. He has a master's degree in economics from the Federal University of Pernambuco, Brazil, in 1987, and in mathematical economics at the Université Catholique de Louvain, Belgium, in 1989. He completed his doctorate in economics, Université Catholique de Louvain, Belgium, in 1992

$\mathrm{He}$ was the executive secretary of ANPEC-Association of National Graduate in Economics Centres, from 2003 to 2004; an advisory committee member of Administration and Economy CNPq CA-AE, from 2005 to 2007. He was a coordinator of the economy area by CAPES, from 2004 to 2006; an area coordinator at CAPES for the three years from 2007 to 2010, being extended for the 2010-2012 period, and elected to the CTC-CAPES Technical Scientific Council for the triennium from 2010 to 2012 (taking it away in May 2012).

Prof. Dr. Ramos has published several articles in professional journals and conference proceedings, and books and book chapters. Such as: "Wastewater allocation to opportunity costs in sugarcane planted areas in Rio Pirapama basin," Economic Studies, 2010; "Analysis of electricity generated by the economic feasibility of microalgae," Systems \& Management, 2011; Modèles Statiques Dynamiques et d'Economie Optimisation d'une Avec Pollution, Louvain-la-Neuve: Ciaco, 1992. He has supervised many dissertations, doctoral theses, undergraduate works and course conclusion monographs. 

Wind \& Tidal Energy, Biogas 
